\title{
Para un humanismo del siglo XXI: desafíos y propuestas
}

\author{
Miguel David Baraona Cockerell \\ Centro de Estudios Generales \\ Universidad Nacional, Costa Rica \\ baraona_miguel@hotmail.com
}

\section{Resumen}

En esta ponencia examinamos el desenvolvimiento de las cuatro crisis principales que confronta la humanidad en los albores del siglo XXI: la crisis ambiental, la crisis económica, la crisis de civilización, y la crisis de hegemonía. En este trabajo mostramos cómo la interacción sistémica entre estas cuatro crisis y la retroalimentación negativa entre ellas plantean una amenaza para la sobrevivencia futura de los seres humanos. Esto representa una encrucijada particularmente compleja y peligrosa, en la cual es probable que la sobrevivencia misma de la especie será decidida. Esta ponencia examina las cuatro crisis mayores e intenta establecer un marco de análisis para entender sus causas y su génesis pasada y presente. En la sección final avanzamos algunas propuestas básicas, pero cruciales, concernientes a la perspectiva humanista, basada, implícita o explícitamente, en el supuesto central de que existe una naturaleza humana esencial que es al mismo tiempo universal y común a toda la humanidad. Esta noción igualitaria, democrática y revolucionaria no ha sido, sin embargo, nunca enteramente incorporada en términos de las prácticas históricas y sociales reales, permaneciendo siempre cercenada y limitada por diferentes dicotomías en distintas sociedades y períodos históricos, separando a 'nosotros los humanos' de 'ellos los subhumanos'. Esta simple pero poderosa noción de que los seres humanos han sido "creados" iguales y comparten la misma naturaleza humana básica es hoy casi auto-evidente, puesto que en la práctica social real nunca ha sido completamente aplicada; continua siendo, conceptualmente, la piedra angular sobre la que podemos erigir e implementar una praxis humanista contemporánea.

Palabras clave: crisis mayores-crisis ambiental-crisis económica-crisis de civilización-crisis de hegemonía-humanismo contemporáneo. 


\begin{abstract}
In this paper we examine the unfolding of the four major crises facing humanity at the dawn of the twenty-first century: the environmental crisis, the economic crisis, the civilizational crisis, and the crisis of hegemony. In this paper we show how the systemic interaction between these four major crises and the negative feedback between them poses a major threat for human future survival. This represents a particularly complex and perilous crossroad, in which most probably the survival itself of our species will be determined. The paper examines all four major crises and tries to establish a frame of analysis for understanding their original causes and their past and present genesis. In the final section, we advance some basic though crucial proposals concerning the emergence of a humanist perspective, based on the implicit or explicit central assumption of an essential human nature which is both universal and common to all of humanity. This egalitarian, democratic and revolutionary notion has never been entirely fulfilled in terms of actual historical and real social practices, remaining always curtailed and jeopardized by different types of dichotomies in different societies and in different historical periods, separating the 'human us' from the 'subhuman them'. This simple though powerful and today almost self-evident truth that all humans are "created" equal and share the same basic human nature, because it has never been totally fulfilled in real social practice, continues to be a conceptual cornerstone from which we can construe and implement a contemporary humanist praxis.
\end{abstract}

Keywords: major crises-environmental crisis-economic crisis-civilizational crisis-crisis of hegemony- contemporary humanism.

Introducción: danzando en la bruma junto al abismo

$\mathrm{E}$ n esta ponencia abordamos los grandes desafíos que la humanidad confronta al entrar a la segunda década del siglo XXI. Los desafíos son de muy diversa índole, y constituyen una red compleja de problemas que se retroalimentan en forma negativa entre ellos y cuya solución, en último término, solo podrá ser de carácter macro-social y mediante enfoques sistémicos que ataquen de raíz las causas esenciales de los fenómenos que hoy ponen en entredicho la sobrevivencia futura de nuestra especie. Para simplificar, se examinan solo las cuatro crisis fundamentales que definen la encrucijada global en que nos encontramos.

En forma sumaria, se describirán la crisis ambiental, la crisis económica, la crisis de hegemonía global y la crisis de civilización, las cuales definen nuestra era como una de las más complejas y peligrosas que haya enfrentado la humanidad.

24 Vol. 1(1), Julio-diciembre, 2013: 11-21 • Revista Nuevo Humanismo・ISSN: 1405-0234

[ pp. 23-46] 
Luego, se hará una síntesis de las propuestas esenciales del humanismo y se discutirán, a la luz de las necesidades perentorias de la humanidad, en la encrucijada histórica contemporánea, que de seguro será la problemática central de nuestra especie a lo largo del siglo XXI, y posiblemente hasta mucho después, debido a las consecuencias a largo plazo de la crisis ambiental, que recién comienza a manifestarse y que es de origen antropogénico.

De esta discusión se rescatarán las ideas centrales del humanismo clásico que aún poseen validez, a las cuales se agregarán también las propuestas nuevas que consideramos indispensables para el desarrollo de una praxis (pensamiento y acción) humanista, adecuada a los desafíos colectivos que enfrentamos hoy.

La ponencia es interdisciplinaria, pues el análisis y la discusión de las cuatro grandes crisis de esta era así lo exigen, y abarca en forma combinada aspectos de disciplinas como la economía, la antropología, la ecología y la filosofía; a la vez, intenta presentar una visión sistémica e integrada para examinar los diferentes temas que se abordan.

En el análisis de la crisis económica se utilizarán información y teorías sobre los ciclos históricos largos de la acumulación de capital, la financiarización de la economía capitalista en su fase, la cuestión de la tendencia a la tasa decreciente de la ganancia, la teoría sobre la tendencia al estancamiento crónico del capitalismo y el capitalismo monopólico y la competencia imperfecta, y la dinámica de las burbujas financieras.

La crisis ambiental se analizará solo desde el ángulo del calentamiento global, que es su aspecto más dramático y de más difícil solución a mediano plazo, y se utilizarán, en parte, los conceptos de la ecología social de Bookchin. La crisis de hegemonía global -que es sobre todo el declive del poderío norteamericano desde el fin de la Guerra Fría- será descrita recurriendo a numerosos autores e información de fuentes diversas, pero partiendo en lo esencial de los trabajos de Chomsky y de Bricmont. En cuanto a la crisis de civilización y la discusión y las propuestas sobre el humanismo actual, nos apoyaremos en nuestros propios trabajos.

\section{La humanidad en la encrucijada: las cuatro crisis}

Se ha llegado a un punto en la historia de la humanidad, en el cual se debe intentar lo imposible para no llegar a lo impensable. Cuatro crisis fundamentales se encuentran en pleno proceso de desenvolvimiento $y$, aunque cada una de estas tiene sus 
propias causas, génesis y prospectos específicos, todas se retroalimentan en forma negativa, y hacen que sea imposible solucionar alguna de manera más o menos definitiva y prolongada, sin enfrentar a las cuatro simultáneamente: la crisis del medio ambiente global, la crisis económica mundial, la crisis de hegemonía en la que el momento unipolar de los años noventa ha demostrado que EE. UU. no puede controlar por sí solo todo el sistema-mundo, y la crisis de nuestra civilización, debido a la vulgaridad, mediocridad y superficialidad de la metacultura capitalista, impuesta al mundo por la globalización neoliberal. Estas cuatro crisis simultáneas forman un cuarteto letal, el cual plantea, quizás, uno de los desafíos más severos que haya enfrentado la humanidad hasta hoy.

\section{La crisis ambiental}

De las cuatro crisis centrales de nuestra era, el deterioro y el caos introducido por la acción antropogénica es, sin lugar a dudas, la más seria y la que mayores desafíos plantea a la humanidad. Estamos experimentando la sexta extinción masiva de especies en la vida del planeta (4 500000000 de años), con aproximadamente 50000 especies de seres vivos (plantas y animales), que desaparecen cada año, lo que es un ritmo de destrucción del tejido vital sobre la tierra absolutamente devastador. Además, los problemas de contaminación del aire, del agua y de los suelos son también alarmantes, junto con la deforestación y desertificación de amplias regiones del planeta. Pero, de todos estos perturbadores fenómenos, el que plantea un peligro mayor para la sobrevivencia futura de nuestra especie -la que con cerca de 180000 años de existencia ha superado ya el promedio de supervivencia de los mamíferos que rara vez supera los 150000 años-, es el cambio climático global ocasionado, a su vez, por el gradual calentamiento promedio de la atmósfera terrestre.

Durante un tiempo, los datos del calentamiento global fueron cuestionados por quienes se sentían aludidos como sus culpables principales y, luego, han resistido de manera fehaciente todo intento por mostrar que este proceso es de origen antropogénico y no natural. Y, hasta cierto punto, han prevalecido y triunfado en países clave como los EEUU, en el llamado "tribunal de la opinión pública", la batalla de la propaganda, de modo que aún hay un porcentaje mayor en este último país de personas que no creen en el fenómeno ni en la explicación científica de sus causas. Sin embargo, en la comunidad científica, especializada en esta clase de fenómenos climatológicos, ya no existe ninguna duda o debate sobre su existencia, su génesis y su origen. La temperatura promedio del planeta está aumentando, y su única causa probada es la actividad humana. Entre 
1900 y 1990 se ha calculado, de manera bastante exacta, que la temperatura global promedio ha aumentado en 0,6 grados centígrados, y que este aumento se correlaciona de manera muy estrecha con el aumento en la emisión de los llamados gases de invernadero (greenhouse gases), que son de origen antropogénico y están ligados, principalmente, a la actividad productiva que depende de los combustibles fósiles, de forma específica de los hidrocarburos (petróleo y derivados) (ver Gráfica 1).

\section{Gráfica 1}

Curvas de calentamiento global y de gases de invernadero, 1900-1990

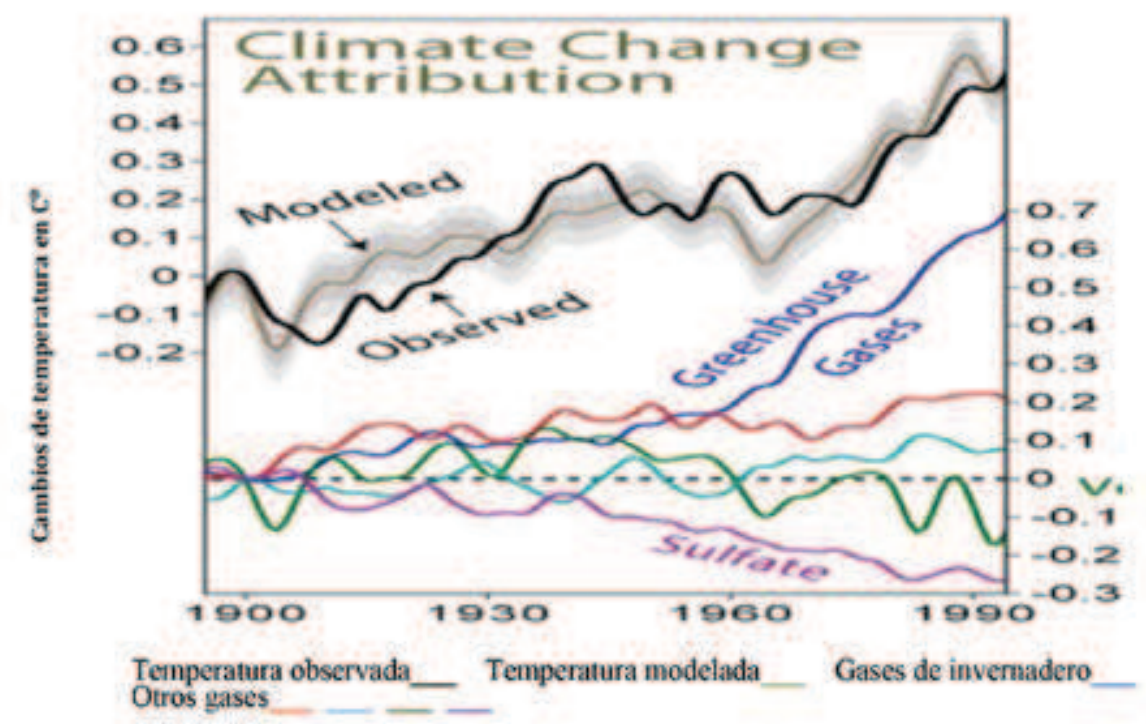

Fuente: Barnett, Pierce, y Schnur, 2001, p. 25.

Durante igual período de tiempo, la elevación mundial promedio de los océanos ha sido de treinta centímetros, debido al derretimiento de los casquetes polares y de los glaciares (Hinrichsen, 1998). Hay estimaciones que señalan que si la temperatura promedio global ascendiera dos grados -es decir, $1,4^{\circ}$ centígrado más que ahora- los niveles de los océanos podrían subir setenta metros más por encima de su nivel actual, lo que, sin duda, sería una catástrofe de dimensiones apocalípticas, puesto que ello supondría que una gran cantidad de asentamientos humanos en áreas costeras quedarían sumergidos en el mar (Wallace, 1999 y 2004). 
Se estimaba en el 2002 que cerca de tres mil millones y medio de personas vivían a menos de doscientos kilómetros de la costa, en alguna parte del orbe (Curran et al., 2002). En otras palabras, una elevación de setenta metros del nivel del mar significaría la destrucción de incontables puertos y grandes ciudades cercanas al mar, así como la destrucción de millones de vidas humanas y de modalidades de vida de pescadores y otros habitantes establecidos en áreas costeras (Tibbets, 2002). Eso supondría, casi de seguro, una total desarticulación de nuestra civilización tal y como la conocemos en la actualidad (Shan Sun y James Hansen, 2003).

Por otra parte, es interesante notar que a medida que la curva de reservas disponibles de petróleo desciende a nivel global, el consumo sigue en aumento generando cada vez más gases de invernadero, medidos en partes por millón de $\mathrm{CO}^{2}$ (ver Gráfica 2). Nuestro afán por consumir volúmenes cada vez mayores de combustibles fósiles parece ser incontenible, aún si ello supone despilfarrar justamente uno de los recursos naturales decisivos para el proceso de modernización y desarrollo capitalista, desde el último cuarto del siglo XIX hasta nuestros días.

\section{Gráfica 2}

Curvas de reservas de petróleo disponibles (\%) y concentraciones de $\mathrm{CO}_{2}$ en la atmósfera (PPM=Partes Por Millón)

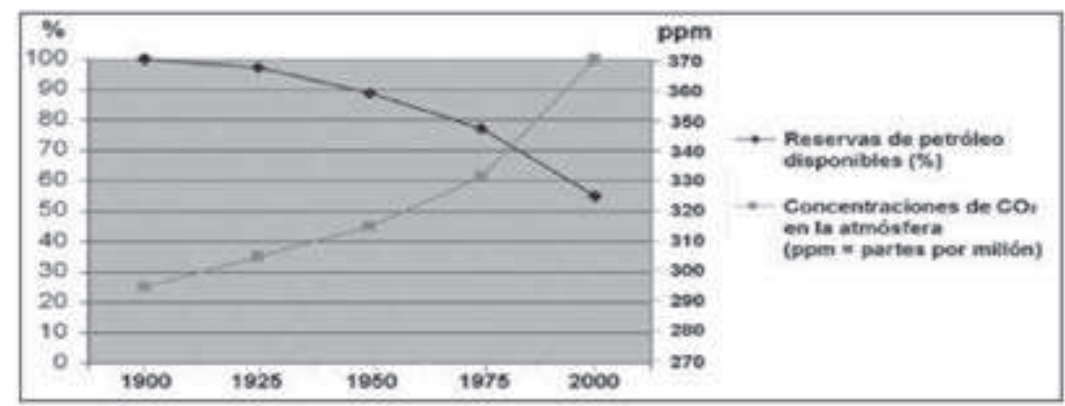

Fuente: BP (Bristish Petroleum), Statistical Review of World Energy 2007. Recuperado de http:// www.bp.com.

Si no somos capaces de poner coto a este uso indiscriminado, y en ascenso, de combustibles fósiles, es muy posible que hacia mediados de este siglo estemos viviendo en un planeta con un clima tan descontrolado que ponga seriamente en peligro la supervivencia misma de la especie.

28 Vol. 1(1), Julio-diciembre, 2013: 11-21 • Revista Nuevo Humanismo・ISSN: 1405-0234 


\section{La crisis económica}

Alrededor de 1975 la gran fase de expansión económica de posguerra llega a su punto máximo de desarrollo y comienza a estancarse y es seguida de un prolongado y progresivo declive. Esto resulta del proceso del efecto acumulativo, macroeconómico y a largo plazo, de la tendencia a la tasa decreciente de la ganancia. Este mecanismo económico, inherente al capitalismo y cuya explicación es demasiado técnica y compleja como para abordarlo en esta ponencia, se expresa históricamente a través de un comportamiento macroeconómico cíclico, en largas fases de expansión con sus inevitables altos y bajos de corto alcance, son seguidas de otra fase igualmente larga con oscilaciones menores y que conduce a una seria depresión (Kondratieff, 1936).

Al terminar la guerra, el Plan Marshall y la reconstrucción de Europa Occidental y del Japón proveen los estímulos indispensables para el comienzo de los que muchos economistas han definido como la edad de oro del capitalismo, o como los "treinta gloriosos" de desarrollo económico mundial (Dossani y Chomsky, 2009), que va de circa 1945 a 1975 (Arrighi, 1994). Es un período de expansión del bienestar popular, sin precedentes en la historia económica moderna, desde comienzos del siglo XIX cuando el capitalismo industrial irrumpe en la escena europea y se extiende al resto del mundo; sin embargo, era solo una fase dentro de un ciclo más amplio, que comprende esa expansión inicial, seguida de otra fase declinante.

A partir más o menos de la mitad de la década del setenta del siglo XX, se inicia un período de estancamiento del desarrollo en favor de las grandes mayorías trabajadoras, y que responde a una presión hacia la contracción crónica de la tasa de ganancia de las empresas capitalistas (David Harvey, 1982). Es parte de un macro ciclo que fuese bien tipificado hace mucho tiempo por el economista ruso Kondratieff, quien a fines del siglo XIX había establecido en forma empírica, mediante una gran masa de datos estadísticos, la morfología de estos largos ciclos capitalistas de expansión, estancamiento y contracción de la economía mundial.

Entre 1945 y 1975, se produce la fase de expansión; entre 1975 y 2007, la de estancamiento (Hankyioreh, 2009); y en el 2008, la de contracción y crisis, que podría ser a su vez el preludio de una nueva fase Kondratieff A de crecimiento, dentro de un nuevo macro ciclo general de la economía capitalista. Así como no puede negarse que existe esa posibilidad de restauración capitalista, hay asimismo la alternativa 
de iniciar procesos de transición al socialismo, en todos aquellos países en los que la resistencia popular se convierta en insurrecciones políticas organizadas y democráticas en contra de la tiranía del capital (Hobsbawm, 2002).

Siguiendo otra línea de análisis anterior, pero que resulta, a mi parecer, complementaria a la de Kondratieff, Marx había argumentado que el capitalismo está regido por lo que él llamó, con un lenguaje característico de la época, la "ley de la tendencia decreciente de la tasa de ganancia". Esta ley fue presentada por él en el tercer volumen de El Capital, pero desgraciadamente no pudo explorar de manera exhaustiva la forma como el capital se adapta a esta limitante endógena. En todo caso, vista dentro del contexto económico catastrófico de hoy, la explicación de Marx asume nuevos ribetes de dramática vigencia (Mandel, 1968, pp. 52-84).

En forma magistral, simple y a la vez profunda, Marx explica cómo a nivel microeconómico de cada empresa, la tasa de ganancia se reduce con cada ciclo productivo si no hay un incremento constante del capital variable (Marx, 1962 (1866) II- XIII, pp. 233-253); es decir, del capital invertido para aumentar la productividad del trabajo en nuevas máquinas, tecnologías y métodos de explotación de la fuerza laboral, y que se convierte, de este modo, en capital fijo, una vez que se incorpora y se agrega a los medios de producción existentes. En otras palabras, la ampliación constante del capital variable, necesario para incrementar la tasa de ganancia, empuja también a una ampliación constante del capital total al convertirse, una vez invertido, en nuevos instrumentos y medios de producción que pasan a conformar parte integral del capital fijo acumulado.

Esta ampliación constante del capital variable mediante, la dinámica recién descrita, implica un sistema económico en permanente necesidad de ampliación en su fase expansiva y, por ende, de competencia acerba entre empresas capitalistas que luchan por el control del mercado y la consiguiente eliminación de sus rivales. Ocurre que la destrucción o absorción de empresas rivales desemboca siempre en la concentración de los medios de producción, y el capital en manos de un número menor de empresas, lo que, en otras palabras, se traduce en monopolios cada vez más poderosos, que imponen condiciones de creciente arbitrariedad, tanto a los trabajadores como a los mercados. Cuando la economía capitalista general alcanza ese punto crítico, en que los monopolios dominan casi completamente el mercado, se inicia una fase Kondratieff B, de estancamiento económico prolongado.

Ese es el talón de Aquiles del capitalismo y la causa primaria, estructural e insoslayable que conduce, a lo largo de muchos recovecos, al monopolio, la sobreproducción,

30 Vol. 1(1), Julio-diciembre, 2013: 11-21 • Revista Nuevo Humanismo • ISSN: 1405-0234 
la caída de los salarios reales, la desigualdad económica creciente entre clases sociales (Milanovic, 2005) y, finalmente, al estancamiento crónico y a las crisis cíclicas. Los tecnicismos que explican en detalle esta ley son demasiado complejos para abordarlos aquí, pero es necesario señalar que los macro ciclos económicos descritos por Kondratieff (un historiador y economista liberal y sin ninguna conexión intelectual con el trabajo de Marx) son la forma exterior y prolongada mediante la cual se manifiesta la tendencia endógena a la caída de la tasa de ganancia general del capitalismo. ${ }^{1}$ Es decir, que esa ley descubierta y descrita por Marx se manifiesta gradualmente y en forma cada vez más acentuada, de manera que luego de un período de expansión sobreviene un estancamiento que precede a una fase declinante, la cual conduce de manera inevitable a una depresión severa cuando se alcanza un punto extremo de sobreproducción y de caída del consumo (Schumpeter, 1935, pp. 2-10; y 1939).

A partir de circa 1973-1975, la presión hacia una tasa de ganancia declinante comienza a aumentar en una forma que será duradera y cada más acentuada. A la tendencia natural a la disminución de la ganancia en el capitalismo, se suman acontecimientos históricos y fenómenos económicos a escala mundial que agravarán, aún más a nivel macroeconómico, el mecanismo macroeconómico básico que empuja a la caída de la tasa de ganancia en cada centro productivo capitalista. Vemos cómo a partir de la década de los sesentas del siglo pasado, se genera un incremento gradual de la competencia al incorporarse, de forma cada vez más amplia e intensa, a la economía mundial, los nuevos poderes capitalistas emergentes, como Europa Occidental (especialmente Alemania), Japón y, posteriormente, los Tigres Asiáticos.

Así llega a su fin, en forma eventual, una fase de expansión económica sin precedente en la historia moderna y comienza, también, el largo descenso hacia la crisis actual. El período de expansión económica de la posguerra (que muchos han denominado los "gloriosos treinta", en referencia a las tres décadas aproximadas de su duración) es de crecimiento notable, de acuerdo con todos los indicadores tradicionales (inversión, salarios reales, PIB, etc.); pero sobre todo es notable

1 Fenómeno que no siempre encuentra una expresión estadística y cuantitativa evidente, pues, como discutiré más adelante en este mismo ensayo, el capitalismo desarrolla numerosos mecanismos de adaptación a la presión constante que ejerce esta limitante endógena, y que consiguen encubrir su manifestación explícita, pero que conllevan a la acumulación de una serie de factores negativos (de los cuales el monopolio, la exportación de empleos a países periféricos que ofrecen mano de obra barata, y las burbujas financieras basadas en la expansión especulativa del crédito, son quizás los más dañinos) que a la larga provocan igualmente el estallido de crisis estructurales muy severas. 
por el avance que se registra en los indicadores sociales, que debieran ser los criterios más importantes para medir la expansión económica, pues no solo nos hablan de crecimiento, sino de desarrollo en su sentido más amplio. En esta fase ascendente del macro ciclo, descrito por Kondratieff, el quintil estadístico con menores ingresos de la población mejora su nivel económico con mayor rapidez que el más alto, lo cual es precisamente lo opuesto de lo que sucede durante la fase declinante. Es la fase en la que el capitalismo puede darse el lujo de beneficiar a ciertas capas asalariadas y, al mismo tiempo, garantizar elevadas tasas de ganancia (Dowd, 2009).

La tasa decreciente de la ganancia, a la que se suma una competencia cada vez más acérrima dentro del capitalismo, empuja hacia la búsqueda de alternativas que permitan sostener un retorno económico más satisfactorio, a nivel de cada empresa en particular, y del capitalismo en general. Varias serán las nuevas estrategias proseguidas por el capitalismo para intentar solventar este problema, y cada una de ellas ayudará a mantener la tasa de ganancia por empresa, a niveles satisfactorios, al tiempo que acentúan las mismas causas que empujan al estancamiento a nivel económico general. Mientras mayor sea el empuje hacia el aumento del capital variable en cada empresa, mayor será también el clima general de competencia entre empresas. Por ello, aunque el efecto global sobre la totalidad del sistema económico será nocivo, ${ }^{2}$ una de estas estrategias a nivel microeconómico consiste precisamente en la intensificación e innovación tecnológica constante, aplicada a la esfera productiva. Ello parecería, en principio, poner de manifiesto la naturaleza progresista del capitalismo, puesto que impulsa en forma permanente el desarrollo tecnológico, basado en la creatividad empresarial y la innovación científica y tecnológica; esto no es más que una ilusión óptica pasajera. La intensificación y renovación tecnológica, aplicada a la productividad, permite sostener los retornos económicos por empresa (Robinson, 1933; Chamberlain, 1933; Blair, 1972), pero tiene, a su vez, el efecto general de agravar la competencia entre capitales antagónicos, la cual conducirá de forma irremediable a la eliminación masiva de los rivales y, por consiguiente, al monopolio.

El monopolio es retrógrado (Baran and Sweezy, 1966) puesto que implica una inversión menor en renovación de los instrumentos productivos, lo que, a su vez, tiene tres consecuencias indeseables que llevan al estancamiento económico general:

2 Sin hablar del impacto depredador constante y en aumento que sobre el entorno natural tendrá tal estrategia.

32 Vol. 1(1), Julio-diciembre, 2013: 11-21 • Revista Nuevo Humanismo・ISSN: 1405-0234 
1. Las bases mismas de la libre competencia son erosionadas, ${ }^{3}$ con lo que se destruye el estímulo económico que impulsa al capitalismo en su fase de auge. ${ }^{4}$

2. Se retrae, además, el impulso progresista del capital hacia la innovación tecnológica y la investigación científica aplicada a la economía.

3. La calidad de los productos desciende y los precios son más elevados. Como consecuencia de la combinación letal de estos tres efectos indeseables de la concentración del capital, el estancamiento económico se vuelve crónico, la tasa de ganancia tiende a reducirse aún más que en condiciones normales de competencia, y la única escapatoria que queda es reducir los salarios reales de los trabajadores.

En el capitalismo monopólico y transnacional de nuestra era, lo anterior se ha conseguido mediante numerosos ardides; pero, sobre todo, por medio de la transferencia del aparato industrial y productivo a aquellos países con más bajos salarios mínimos y con mayores facilidades para ejercer, en forma descarnada, la explotación del trabajo. De modo que, al final de cuentas, la globalización transnacional impulsada por el neoliberalismo no es más que la expresión tangible de esta estrategia del capitalismo monopólico (Bellamy, 1986, pp. 52-56).

3 Según William G. Shepherd, las empresas oligopólicas impiden la libre competencia impidiendo el ingreso a ciertos nichos del mercado dominados por ellos, mediante veintidós barreras u obstáculos que resultan casi insuperables para cualquier nuevo y potencial competidor: 1 . Requerimientos de capital; 2. Economías de escala; 3. Ventajas absolutas de costo; 4. Diferenciación del producto; 5. Sunk costs: gastos retrospectivos que no son totalmente recuperables. Por ejemplo: el envejecimiento y la pérdida de valor de ciertos instrumentos e infraestructura productiva; 6. Intensidad de la investigación y desarrollo de la empresa; 7. Asset specificity: es decir, la aplicación, transacción o inversión específica más redituable posible de ciertos activos tienen dentro de un abanico de opciones; 8 . Integración vertical; 9. Diversificación de acuerdo con los conglomerados existentes; 10 . Variando costos dentro de un sistema complejo; 11. Ciertos riesgos e incertidumbres especiales; 12. Asimetría en la información; 13. Barreras formales establecidas por los Estados; 14. Acciones para prevenir incorporación de nuevas empresas a un mercado ya controlado por grupos económicos existentes; 15. Capacidad para generar excesos; 16. Gastos de venta, incluyendo la publicidad; 17. Segmentación del mercado; 18. Patentes; 19. Control exclusivo de ciertos recursos estratégicos; 20. Emprender acciones que aumentan los costos de los rivales; 21. Una elevada y constante diferenciación del producto; 22. Capacidad para mantener el secreto en torno a las condiciones de la competencia.

4 Y ello a pesar de toda la retórica vacía del discurso oficial en favor del libre mercado (Perelman, 2005).

ISSN: 1405-0234 • Revista Nuevo Humanismo • Vol. 1(1), Julio-diciembre, 2013: 11-21. 
En el pasado, mientras los mercados domésticos operaban como compartimentos estancos relativamente separados y bajo el control omnímodo de los capitalistas nacionales, la competencia a escala planetaria entre distintos centros nacionales capitalistas se agravó considerablemente, en especial, luego del fin de la Segunda Guerra Mundial. De esta forma, los mercados domésticos cautivos eran en parte erosionados mediante el capital monopólico nacional en auge; pero, a nivel internacional, la rivalidad ${ }^{5}$ se intensificaba de manera tal que las empresas foráneas continuaban representando un serio peligro para los monopolios nacionales que habían conseguido eliminar a sus rivales internos, ${ }^{6}$ o convivir con ellos al especializarse en distintos nichos de consumo.

El ejemplo más palpable de ese proceso lo constituye la industria del automóvil, gran motor dinámico de la economía capitalista de posguerra. Luego de que GM, Chrysler y Ford consiguen aplastar a sus otros competidores menores en los Estados Unidos, proceden a compartir, con pocas áreas reales de fricción, el mercado doméstico cautivo que esto genera, y se establecen así como capitales monopólicos sobre la base de destruir los fundamentos del libre mercado (Harvey, 2005). Luego de algunos años de bonanza, el regreso económico triunfal de Europa Occidental, Japón y otros países asiáticos representa el surgimiento de nuevos y cada vez más enconados rivales económicos internacionales, que empiezan a desplazarlos de los mercados mundiales y, finalmente, a destronarlos dentro del propio mercado nacional norteamericano (Steindl, 1974).

Así surgen las corporaciones transnacionales (Hymer, 1976) que intentan distribuir geográficamente diversas ramas de la producción y administración, en un conjunto de distintos países que les ofrecen ventajas comparativas desde diversos puntos de vista: salarial, impositivo, regulaciones ambientales, leyes laborales, infraestructura, entre otros. Este impulso hacia la formación de enormes empresas transnacionales nace del poder económico de los monopolios que puede abarcar todo el planeta, con sus redes de inversión y manufactura; y de la necesidad de abaratar costos de producción, sobre todo accediendo a mano de obra barata (Kolko, 1988). Con este fenómeno de grandes proporciones se inicia un nuevo ciclo de globalización, el cual se torna más extenso y profundo a medida que la fase Kondratieff B, de declive gradual, domina cada vez más la escena económica global. Este declive, que genera una globalización al servicio de los intereses de

5 Para una mejor comprensión de la diferencia conceptual entre 'competencia' y 'rivalidad' dentro del contexto teórico de la economía neoclásica (Bellamy Foster, McChesney and Jonna, 2011).

6 O asociarse con ellos.

34 Vol. 1(1), Julio-diciembre, 2013: 11-21. Revista Nuevo Humanismo • ISSN: 1405-0234 
las transnacionales, alcanzará su culminación en la década de los noventa, cuando el neoliberalismo se convierte en la doctrina económica oficial del capitalismo.

La desregulación creciente de los mercados financieros, que promueve el neoliberalismo desde fines de los ochenta, permite no solo la expansión del capital transnacional a partir de las libres inversiones y la libre comercialización, sino también la repatriación, sin límites ni regulaciones, de las ganancias (Baraona, 2005). El capital transnacional manufacturero y de servicios, que surge con ímpetus al entronizarse el neoliberalismo, se comienza a estancar de nueva cuenta, debido a los grandes monopolios que dominan ramas enteras de la economía y sofocan el mercado, ${ }^{7}$ la caída de los salarios reales (Dowd, 2009), la cada vez mayor desigualdad entre los dos quintiles más elevados y los dos quintiles más bajos de la pirámide de la rique$\mathrm{za}^{8}{ }^{8}$ y a la competencia, día con día más ríspida entre megaempresas capitalistas que luchan por aniquilarse o devorarse las unas a las otras. Ya desde inicios de los años ochenta -poco antes del ascenso del neoliberalismo y, como de costumbre, frente al estancamiento prolongado del capitalismo- se comienzan a recorrer las conocidas etapas (Minsky, 1993) que conducen a las burbujas financieras que sustituyen cada vez más al ciclo económico normal de producción y consumo, con la inflación monetaria y la especulación desenfrenada (Sweezy, 1994, pp. 1-12).

Es una conjura delirante, pues a pesar de ser tan fecunda en ganancias para sus principales protagonistas, es impelida por la corrupción y la ambición descontrolada de un capitalismo terminal (Perelman, 2005), que solo consigue ahora crecer mediante la especulación y el riesgo (Kotz, 2009, pp. 305-317; Palley, 2008 y 2009). Se trata de una dinámica especulativa en apariencia infinita, pero que se nutre de sus propias entrañas en un movimiento acelerado y sin descanso hacia adelante, y que está destinado a desplomarse tarde o temprano con estrépito (Cassidy, 2009). Y ello ocurre, por fin, en julio del 2007, cuando Wall Street se estremece al ver con pánico cómo se derrumba el gigante financiero Bear Sterns, quien admite de manera pública, la insolvencia de dos de sus principales fondos de inversión. ${ }^{9}$ Esto echa a rodar una bola de nieve que no ha cesado de crecer

7 Lo que en forma irónica se produce paralelamente con el auge de la retórica económica y política sobre el "libre mercado", ese espejismo ideológico que nunca se convierte en realidad en el capitalismo.

8 Expresado desde el punto de vista estadístico, en coeficientes de Gini que revelan desigualdades abrumadoras y crecientes entre ricos y pobres, en casi todos los países del orbe; pero, sobre todo, en aquellos en los que el neoliberalismo avanza con mayor éxito, como Chile, por ejemplo, que pasa a incorporarse al grupo de las diez economías más desiguales del orbe.

9 Que contenían valores altamente especulativos, sostenidos por hipotecas de escasa o ninguna confiabilidad. 
hasta hoy, y que sorprende tanto a "expertos" financieros como a la población en general. De este modo, una prolongada crisis estructural que despunta a mediados de los setenta, resultado del estancamiento que produce la caída histórica y general de la tasa de ganancia, y que ha sido enmascarada durante mucho tiempo por medio de burbujas financieras cada vez más grandes, estalla, y pone al descubierto las debilidades inherentes a todo el sistema capitalista.

La real magnitud de la burbuja financiera, que aún está en proceso de desinflarse, es un misterio para todos, puesto que los bancos ocultan y desconocen el tamaño real de sus propios créditos y bienes financieros tóxicos. Según algunos, esta burbuja habría alcanzado proporciones tales (Beinstein, 2009) que supera con creces al conjunto de la economía mundial. Si esto fuese así, ello implicaría que no hay suficiente dinero en todo el mundo para apagar esta conflagración, y que resulta una total futilidad intentar hacerlo con los diversos paquetes de rescate y estímulo que se han arrojado a la hoguera, sin importar cuán grandes estos sean. Al final del día el incendio financiero, que avanza sobre la llanura económica, reseca y propicia a su incineración, terminará devorando igualmente todos esos esfuerzos desesperados por apagarlo.

Hay que insistir en que la crisis financiera no es más que la punta del iceberg, o la consecuencia y el detonante de la actual depresión, ya que en último análisis son las prolongadas dificultades para elevar la tasa de ganancia del capital, a partir de los años setenta, las causas profundas que subyacen en las aguas procelosas de este maremoto económico. Al estallar, la burbuja financiera ha desencadenado, con todas sus fuerzas apenas contenidas hasta hoy, el factor esencial que domina los procesos económicos mundiales y que, oculto tras las bambalinas, ha determinado la marcha de la economía global durante los últimos treinta y cinco años.

Las otras dos grandes crisis económicas mundiales (Crisis de Pánico Financiero de 1873-1880, y la Primera Gran Depresión 1929-1939) que han aquejado al capitalismo -aparte de una centena de otras de menor envergadura- terminaron en sendos conflictos bélicos de gran amplitud, duración y terribles consecuencias. La Primera Guerra Mundial (1914-1918) y la Segunda Guerra Mundial (19391945) fueron la consecuencia diferida en el tiempo de estas dos crisis que dejaron al mundo capitalista sacudido hasta sus cimientos e incapaz de resurgir de nuevo mediante sus propias capacidades económicas intrínsecas, y que solo pudo transitar hacia una fase expansiva mediante el recurso a una solución tan dramática como estas dos conflagraciones militares terribles.

36 Vol. 1(1), Julio-diciembre, 2013: 11-21 • Revista Nuevo Humanismo・ISSN: 1405-0234 


\section{La crisis de civilización}

La crisis de civilización que experimentamos en nuestros días es de carácter sistémico, y tiene dos vertientes: 1. Por un lado, es la crisis específica de la hegemonía cultural de occidente sobre la totalidad de la humanidad, que se fue estableciendo a partir del siglo XVI, y que ahora ha visto su poder de antaño corroído, al igual que toda la vida cultural moderna, por la emergencia de la metacultura corporativa capitalista, la cual, sin duda, canaliza e implementa elementos culturales occidentales, pero en su versión más pedestre; 2 . Y la crisis general de la vida cultural moderna: crisis que tiene que ver con el gradual, pero cada vez más devastador, deterioro de la vida cultural de la humanidad y el empobrecimiento, la estandarización y homogenización de nuestros horizontes, símbolos, normas, valores y tradiciones a medida que la metacultura corporativa y transnacional, propia del capitalismo hipermoderno y avanzado, invade y coloniza cada nicho cultural de la humanidad, en una búsqueda insaciable del lucro y de las ganancias que permitan la acumulación de capital. La hegemonía ideológica global establecida por la metacultura corporativa, fundada a su vez en la simple noción de que el principio del lucro y del consumismo deben gobernar, incluso nuestra vida cultural, ha resultado en un deterioro creciente de la producción simbólica e intelectual mediante dos mecanismos complementarios: 1. La conversión de los bienes y productos culturales en mercancías; 2. La marginalización de toda expresión cultural más sofisticada y compleja, en aras de favorecer a productos y bienes culturales de mayor vulgaridad, y que en virtud de ello circulan mejor en un mercado cultural en el cual los estándares que rigen el gusto masivo han sido ya implantados férreamente por medio de los instrumentos propagandísticos y de adoctrinamiento, apropiados para asegurar una alta demanda (Baraona, 2005 y 2011).

La cultura de masas en los umbrales de la híper modernidad se ha convertido esencialmente en la cultura del voyerismo consumista y de la alienación individual y colectiva, pues permite que productos y bienes culturales cada vez más carentes de significado y de sentido trascendente triunfen en el mercado cultural propio de la metacultura corporativa. Así, el consumismo, el mercantilismo y el tecnologismo a ultranza constituyen en el presente los tres instrumentos ideológicos mediante los cuales se impone la meta cultura corporativa capitalista, a nivel mundial.

En vista de la situación que vive la humanidad a principios del nuevo milenio, el analista está tentado a desarrollar una imagen bastante sombría. Con frecuencia, nos enfrentamos a la modernidad en términos que son paradójicamente más prosaicos, pero a la vez más dramáticos que los modernistas del siglo XIX: hoy 
confrontamos la modernidad como quien mira en un espacio completamente vacío. Extendemos nuestra mirada sobre este gran abismo cultural y espiritual, y solo podemos vislumbrar el reflejo en sus márgenes de pequeñas modas cambiantes que compiten entre sí. Las vemos nacer y perecer en apenas un instante, incluso, antes de que hayamos tenido tiempo siquiera de descubrir el sentido de sus breves existencias. Las vemos brillar para luego apagarse, caer hacia el vacío, y precipitarse desde los márgenes activos en los que se efectúan, sin pausa, las operaciones del mercado capitalista. Desde allí se desploman hacia el centro oscuro del gran hueco voraz de la modernización, donde se trituran sin pausa no solo las pequeñas modas irrelevantes, sino también el pasado, las tradiciones, las identidades, y las certidumbres. La modernidad, en esta visión pesimista, ocupa el centro de nuestra vida cultural contemporánea como un "agujero negro"; como una gigantesca vorágine creada por procesos de modernización capitalista insaciables, por nuevos y efímeros símbolos y productos de las industrias culturales, a los que rápidamente devora en una fuite-en-avant hacia el aniquilamiento final de todo significado (Barel, 1984).

Pero esa visión pesimista, y que enfatiza solo un aspecto de la modernidad, es por fuerza muy parcial. Por un lado, es cierto que la modernidad, entendida como un modelo ideal hacia el cual la sociedad debe evolucionar, ha perdido toda relevancia histórica. Por otro, la modernidad se define cada vez más como un campo de conflictos y tensiones, asociados a la modernización, que como un campo delimitado por certidumbres ideológicas, o ideales y objetivos políticos altruistas; por ello es fácil, y relativamente común, percibir la modernidad como un simple "agujero negro" en torno al cual se tejen solo conflictos, en el mejor de los casos, o una sucesión de modas, en el peor.

\section{La crisis de hegemonía}

Desde los orígenes del sistema-mundo moderno que nace y emerge luego del "descubrimiento" de América en 1492, esta gran estructura económica y política global ha estado bajo el control hegemónico de alguna gran potencia. España fue el primer hegemón global, seguido por Holanda, la que a su vez fue sustituida por Inglaterra, la que luego de la Segunda Guerra Mundial cedió la primacía a los EEUU. En cada etapa histórica del desarrollo del sistema-mundo (Arrighi, 1994; Wallerstein, 1979), una potencia hegemónica ha impuesto sus intereses y su visión "civilizatoria" al resto de la humanidad por medio de un cierto tipo específico de globalización y de modernización capitalista.

38 Vol. 1(1), Julio-diciembre, 2013: 11-21 • Revista Nuevo Humanismo・ISSN: 1405-0234 
Al terminarse la Guerra Fría (CIRCA, 1990), las élites del poder norteamericanas diseñaron un plan de dominación global para establecer lo que ellos denominaron como el "nuevo siglo Americano". Esta resultó ser una ambición desmedida, y aunque los EEUU consiguieron mantener al principio una hegemonía unipolar, las guerras fallidas en el Medio Oriente, la creciente independencia de América Latina, y la pérdida de influencia y poderío general debido también a su declinante economía, han probado que los EE. UU. es incapaz de gobernar a su antojo los destinos de toda la humanidad.

Lo anterior significa que por primera vez, en cerca de quinientos años, el sistema-mundo carece de un centro hegemónico bien establecido, lo que ocurre, además, en una fase de gran caos económico y político. Esta es una situación compleja que encierra grandes peligros, al igual que grandes oportunidades, para el progreso futuro de la humanidad.

Es necesario, sin embargo, resaltar que la crisis de hegemonía es hasta cierto punto una de las cuatro crisis que tiene consecuencias positivas: la de permitir que diversos pueblos y naciones del orbe puedan escoger con mayor libertad sus caminos hacia el porvenir; al mismo tiempo representa indiscutiblemente grandes peligros derivados del hecho de que casi todo período de transición de un hegemón global a otro ha ido acompañado de graves conflictos bélicos, los cuales con el armamento existente hoy, bien podría conducir a una hecatombe de enormes proporciones. Hemos entrado en un período de turbulencia social, política y económica, y es posible que esta fase marque, entre otros, el fin de la hegemonía global de los EE. UU.

En la actualidad, los EE. UU. aún se autodefine como adalid global de los derechos humanos y civiles, la democracia, y el respeto igualitario a las leyes. No obstante, esto no se condice con una larga historia de violación de todos estos preceptos, y que es demasiado copiosa como para volver sobre esta en el marco limitado de esta ponencia. Ni siquiera podemos remontarnos a las últimas intervenciones militares en Irak y en Afganistán; pero, baste señalar que durante la actual administración demócrata del presidente Obama, la campaña de asesinato de presuntos terroristas en Afganistán y en Paquistán mediante drones teledirigidos ha significado la muerte de entre 2000 a 4000 civiles inocentes, definidos como "daño colateral". En otros términos, igual de elocuentes, se calcula que por cada presunto terrorista asesinado se han producido 50 muertes de civiles inocentes, quienes tenían la "mala suerte" de encontrarse en el lugar y momentos equivocados. Esto constituye no solo una violación flagrante del debido proceso para los 
presuntos terroristas, sino que es una terrible violación de los derechos humanos de todas las víctimas inocentes que esta política de "asesinatos selectivos" ha representado (Chomsky, 2009).

\section{Conclusiones: humanismo del siglo XXI, desafíos y propuestas}

1. El ser humano es una especie que no puede existir sin definir una imagen (o varias imágenes concurrentes, o en competencia) de sí mismo que le sirva de sustento para su identidad individual y social. Si se acepta que el humanismo es en lo fundamental una narrativa y un discurso sobre la naturaleza o esencia del ser humano (Abel, 1992), entonces se debe admitir que la humanidad ha gestado un verdadero caleidoscopio de humanismos a lo largo de sus 180.000 años de existencia, expresados en sus mitos, religiones, arte, filosofía, prácticas económicas, jerarquías políticas, patrones migratorios, relaciones sociales, guerras, etc. Cada acto individual y social, en el transcurso de esos milenios, ha sido la manifestación tangible, aunque a menudo oblicua y poco evidente, de alguna visión ideológica sobre la naturaleza humana y, por lo tanto, un tipo de humanismo.

2. A menudo, esos diversos tipos de paleo-humanismo (o sea, anteriores al surgimiento de un discurso articulado y explícito sobre la homogeneidad básica de la naturaleza humana), se distinguían por hacer una fuerte dicotomía entre 'nosotros' (los verdaderos humanos) y 'ellos' (los infra-humanos), de modo que la esencia o naturaleza humana era solo una propiedad de un grupo en particular, y no de toda la humanidad.

3. En la Grecia Antigua (siglo V antes de nuestra era) surge por primera vez un discurso expresado en la forma de una doctrina igualitaria, o sea, de homogeneidad y unidad básica de la naturaleza humana, el humanismo como lo entendemos, en gran medida en la actualidad. Se trata de una doctrina humanista que se encuadra dentro de la visión arcaica del 'nosotros los humanos', en contraste con 'ellos los infra-humanos'; es decir, los esclavos, los bárbaros y todos los otros pueblos o "razas" de "probada" inferioridad. Aun así, la doctrina humanista igualitaria de los griegos es inclusiva de toda la nación griega, y sirve de este modo para establecer un sistema legal y político, con derechos civiles y humanos que incluyen a todos los griegos, y excluyen, por supuesto, a los 'infra-humanos', quienes son relegados a una categoría diferente poblada por los esclavos y los "pueblos bárbaros". Sin esa doctrina humanista igualitaria, que abarca solo 
a los griegos, la limitada democracia griega hubiera sido imposible. Los romanos no hicieron más que replicar esta visión dicotómica que separaba al nosotros humanos del ellos no-humanos, llevándola a un nivel superior de brutalidad en la era decadente del imperio: y que se expresa no solo en la amplitud de la institución esclavista, sino que lleva además a la crueldad extrema del circo romano, la masacre de cristianos, la destrucción despiadada de la nación judía y de otros pueblos y grupos étnicos, la sangrienta represión de los levantamientos libertarios como el liderado por Espartaco, $\mathrm{y}$ al uso terrible de los gladiadores como negocio y como medio de diversión y alienación popular. La naturaleza humana igualitaria pregonada por el humanismo greco-romano (Stevenson y Haberman, 2004) sigue siendo una visión dicotómica, que divide y segrega a la humanidad entre los humanos (griegos y romanos) y los infra-humanos, que son casi todos los demás (Baraona, 2011).

4. En la Edad Media hay atisbos significativos de la influencia de algunos ideales humanistas igualitarios, nacidos posiblemente de la influencia del Renacimiento y de la Edad de Oro islámica en la Península Ibérica y que, luego, impregnaría poco a poco al resto de Europa. No es de extrañar que el primer antecedente político y jurídico de la famosa Magna Charta Libertatum (Inglaterra, 1215) se haya producido con anterioridad en España, en las Cortes de León de 1188. Entre otras cosas, se dictaminó el derecho al debido proceso, la separación de la Iglesia del Estado, la inviolabilidad del domicilio y del correo, la necesidad del rey de convocar Cortes antes de hacer la guerra o declarar la paz, y se garantizaban numerosos otros derechos individuales y colectivos. En esta Carta Magna Leonesa se promulgaron leyes más igualitarias destinadas a proteger a los ciudadanos comunes y sus bienes, contra los abusos y las arbitrariedades del poder de los nobles, del clero y del propio Rey. Es, quizás, la raíz histórica del humanismo político y jurídico igualitario de la revolución liberal de siglos posteriores (Keane, 2009).

5. El Renacimiento retoma algunas de las ideas cardinales del humanismo greco-romano e intenta ir un poco más lejos pregonando la noción de agencia humana, con más fuerza que su antecesor de la antigüedad; vale decir, del ser humano como gestor de su propio destino (Giordano, 2009 y 2011). En este caso, la dicotomía entre 'nosotros y 'ellos' pierde algo de su carácter estrictamente etnocéntrico y se transfiere a una nueva concepción, más implícita que explícita, en que la línea de separación entre los humanos y 
los no-humanos tiene un carácter de clase que excluye de los beneficios del humanismo igualitario, a las grandes masas populares rurales y urbanas (al menos el 95\% de la población). Es un humanismo igualitario que solo incluye a las élites, pero que diferencia de la noción medieval y feudal de que el orden social desigual es expresión de la voluntad divina; concibe la separación entre 'nosotros con derechos humanos' y 'ellos desprovistos de estos derechos', como resultado de un orden social, producto de la voluntad humana y de la distribución natural y desigual de talentos y virtudes entre los individuos pertenecientes a las élites y aquellos, al vulgo. Es el origen de una perspectiva clasista que concibe que las diferencias de clase, y de derechos y prerrogativas entre diversos estamentos sociales y económicos son expresión de dos tipos de naturaleza humana que lleva a algunos al pináculo del éxito social, y a otros los condena a subsistir en condiciones infra-humanas al fondo del orden social. Sin esta noción central que subsiste y desafía cualquier propuesta humanista igualitaria, el surgimiento del capitalismo y del sistema-mundo moderno y profundamente desigual, habría resultado inviable.

6. La revolución ideológica liberal de los siglos XVII y XVIII (Hobbes, Locke, Rousseau), propuso la novedosa idea de la soberanía popular, fundada en turno en los derechos civiles individuales y colectivos, sentando así las bases para una buena parte de los discursos igualitarios que emergen durante el siglo XIX, y cuya expresión más avanzada serían las ideas socialistas, y su transferencia de la intelectualidad progresista a la clase obrera. Era una ampliación de las nociones humanistas del Renacimiento, al aplicar los ideales igualitarios a la esfera política, al ámbito jurídico, y a los sistemas de gobierno.

7. Sin embargo, los ideales políticos y jurídicos igualitarios del liberalismo clásico no llegarían a fructificar sino de manera muy limitada, y con gran lentitud, y luego de grandes luchas populares y conflictos sociales agudos. Las sociedades modernas verían el avance progresivo de instituciones políticas y sistemas constitucionales más democráticos; pero nuevos y poderosos mecanismos para reducir la democracia a un mero cascarón, desprovisto de verdadero contenido participativo y representativo, emergieron a lo largo del siglo XIX. Se ha impuesto la idea de que la humanidad posee una sola y compleja naturaleza humana (Cumming, 1969) pero en la práctica social, política e incluso jurídica real, las sociedades modernas continúan funcionando acorde con la vieja y en apariencia insalvable dicotomía de 
'nosotros humanos' versus 'ellos subhumanos' (Chomsky, 1996). En las sociedades más abiertas, y con una institucionalidad en apariencia más democrática, se fueron gestando poderosos instrumentos de manipulación mediática e informativa, y el uso extensivo e intensivo de la propaganda, como mecanismo de adoctrinamiento y de manipulación, se hizo extremadamente sofisticado, y desafió incluso las más extravagantes de las imágenes presentadas por George Orwell en varias de sus obras más famosas. El famoso modelo de propaganda elaborado por Edward S. Herman y Noam Chomsky, destinado según estos dos autores a crear "consenso manufacturado" y el "efecto de falso consenso", expuesto en su obra Los guardianes de la libertad (Chomsky y Herman, 1988), explica de manera profunda y convincente este proceso.

8. Frente a los desafíos que confronta la humanidad en la actual coyuntura, los siguientes puntos son esenciales para definir un humanismo del siglo XXI, a nuestro juicio:

a. Debe ser un humanismo que defienda la noción de un medio ambiente, sustentable y apto a largo plazo, para mantener de esta forma la red compleja de la vida, en la cual está suspendida inextricablemente también la existencia de nuestra especie. En este sentido, el humanismo antropocéntrico renacentista que concebía al ser humano como amo y señor de la naturaleza, y como aquel destinado en forma prometeica a domar a su antojo las fuerzas del mundo natural, debe ser descartado debido a su obvio anacronismo y a las peligrosas consecuencias que ha tenido y que ya no pueden ser eludidas. Mientras se siga abordando el tema de la sustentabilidad del medio ambiente, sin asumir cuál es el motor principal de la destrucción sistemática y acelerada de la naturaleza, cualquier postura humanista al respecto será solo una proclama vacía y carente de verdadero asidero intelectual, político y social.

b. Debe ser un humanismo integral que considere la totalidad de las necesidades humanas, y que promueva el avance hacia una mayor igualdad socio-económica entre distintos quintiles de la pirámide de ingresos y de la riqueza, así como la mayor igualdad entre naciones, una tarea central e ineludible. 
c. Debe ser un humanismo crítico de toda forma de militarismo y de intervencionismo -incluyendo aquel que se hace en nombre de los derechos humanos- bélico para mantener el sistema de dominación internacional, en cuya cúspide se encuentra la hegemonía norteamericana.

d. Debe ser un humanismo que se oponga a la imposición del lucro, como único principio rector, en áreas decisivas de la vida humana como son: la salud, la educación, la alimentación, las pensiones, y la vivienda. Estos debieran ser derechos y garantías sociales que no sean meramente retóricos, sino que constituyan obligaciones vinculantes de los Estados.

e. Debe ser un humanismo que se oponga al desmantelamiento de los grandes sistemas de previsión social, que se constituyeron en el período de posguerra y que florecieron durante la fase expansiva del capitalismo (1945-1975), y que hoy, al final de la fase declinante, están seriamente amenazados por las llamadas políticas de "austeridad".

f. En tanto educadores, académicos y universitarios, debemos oponernos a la entronización del lucro y la privatización empresarial en el ámbito específico de la educación universitaria pública, que debe continuar siendo gratuita y de acceso universal, y sostenida íntegramente por los Estados. Y en cuanto al conjunto de la educación superior, incluyendo las universidades privadas, debemos oponernos al aumento desmedido de los aranceles y de las matrículas.

g. En tanto promotores y gestores culturales, debemos oponernos a la vulgarización cultural mercantil, promover bienes y productos culturales de calidad, y exigir que los medios -sobre todo audiovisuales como el cine y la TV- den espacios significativos para que en ellos circulen y se difundan esas creaciones intelectuales, científicas y artísticas que poseen un valor más trascendente que las simples modas pasajeras, y que son promovidas en forma tan asidua y cuya única importancia reside en las ganancias pecuniarias que generan. Oponernos, además, a la errónea idea de que las grandes mayorías son incapaces de apreciar bienes y productos culturales de alto valor intelectual, científico y artístico; y que la cultura de mayor sofisticación es solo para pequeños grupos elitistas.

44 Vol. 1(1), Julio-diciembre, 2013: 11-21 • Revista Nuevo Humanismo • ISSN: 1405-0234 


\section{Referencias}

Arrighi, G. (1994). The Long Twentieth Century: Money, Power and the Origin of Our Times. England: Verso.

Baran, P. A. y Sweezy, P. M. (1966). Monopoly Capital. Nueva York: Monthly Review Press.

Baraona, M. (2005). Puntos de fuga: el fin de una historia y la transición a la hipermodernidad. Chile: LOM Ediciones.

Baraona, M. (2011). Diez ensayos críticos. Costa Rica: Editorial Germinal.

Barel, I. (1984). La societe du vide. Paris: Seuil.

Barnett, T. P., D. W. Pierce y Schnur, R. (2001). Detection of Anthropogenic Climate Change in

the World's Oceans. Science 292: 270-274.

Beinstein, J. (3 de marzo, 2009). Señales de implosión. Rebelión. Recuperado de www. rebelion.Org/noticia.php?id=81659.

Bellamy Foster, J. (1986). The Vulnerable Planet. Nueva York: Monthly Review Press.

Bruno, G. (2009). La sombra de las ideas. De umbris idearum. Madrid: Siruela.

Bruno, G. (2011). De la causa, principio y uno. Buenos Aires: Editorial Lozada.

Cassidy, J. (2009). How Markets Fail. Nueva York: Farrar, Strauss y Giroux.

Chomsky, N. (1996). Powers and Prospects: Reflections on Human Nature and the Social Order. London: Pluto Press.

Chomsky, N. (29 octubre, 2009). Human Rights in the New Millennium: It is Significant that the U.S. is Self-exempted from International Law. Conferencia en London School of Economics.

Cumming, R. D. (1969). Human Nature and History: A Study of the Development of Liberal Political Thought. Chicago: Chicago University Press.

Curran, S., Nash, J.G. y Souza de, R.M. (2002). Interactions Between Coastal and Marine Ecosystems and Human Population Systems: Perspectives on How Consumption. Mediates This Interaction. Ambio: A Journal of the Human Environment 31(4): 264-68.

Dossani, S., Chomsky, N. (2009). Understanding the Crisis-Markets, the State and Hypocrisy. Noam Chomsky's ZSpace Page (18 de febrero).

Dowd, D. (2009). Inequality and the Global Economic Crisis. Londres: Pluto Press.

Hankyioreh, S. J. (24 de febrero, 2009). Un análisis histórico-económico clásico de la actual crisis. Entrevista a Robert Brenner. Rebelión.

Harvey, D. (1982). The Limits to Capital. Chicago: University of Chicago Press.

Harvey, D. (2005). A Brief History of Neoliberalism. Nueva York: Oxford University Press.

Hymer, S. H. (1976). The International Operation of National Firms: A Study of Direct Foreign Investment. Massachussets: MIT Press.

Hobsbawm, E. (2002). Historia del siglo XX. Buenos Aires: Editorial Crítica.

Keane, J. (2009). The Life and Death of Democracy. Londres: Simon \& Schuster.

Kolko, J. (1988). Reestructuring the World Economy. Nueva York: Panteón.

ISSN: 1405-0234 - Revista Nuevo Humanismo • Vol. 1(1), Julio-diciembre, 2013: 11-21. [pp. 23-46] 
Kotz, D. M. (2009). The Financial and Economic Crisis of 2008. Review of Radical Political Economics, 41(3).

Mandel, E. (1968). La formación del pensamiento económico de Marx de 1843 a la redacción de El capital: estudio genético. Argentina: Siglo XXI.

Marx, K. (1968). Introducción a la crítica del derecho de Hegel. Buenos Aires: Editorial Claridad.

Milanovic, B. (2005). La era de las desigualdades. Dimensiones de la desigualdad internacional y global. Madrid: Editorial Sistemas.

Minsky, H. (1993). Financial Instability Hypothesis. Handbook of Radical Political Economy. Arestis y Sawyer (eds.). New York: The Jerome Levy Economics Institute.

Palley, T. I. (11 de abril, 2008). America's Exhausted Growth Paradigm. Chronicle of Higher Education.

Palley, T. I. (julio, 2009). America's Exhausted Paradigm: Macroeconomic Causes of the Financial Crisis and the Great Recession. New America Foundation (July 22).

Perelman, M. (2005). Railroading Economics: The Creation of the Free Market Mythology. Nueva York: Monthly Review Press.

Robinson, J. (1932).The Economics of Imperfect Competition. London: Macmillan. Schumpeter, J. A. (1935). Análisis del cambio económico. Ensayos sobre el ciclo económico. The Review of Economic Statistics 17(4).

Schumpeter, J. A. (1939). Business Cycle: A Theoretical Historical and Statistical Analysis of the Capitalist Process. Philadelphia: Porcupine.

Steindl, J. (1974). Maturity and Stagnation in American Capitalism. Nueva York: Monthly Review Press.

Stevenson, L. y David L. H. (2004). Ten Theories of Human Nature. Nueva York: Oxford University Press.

Sweezy, P.M. (1994). “The Triumph of Financial Capital”. Monthly Review (June).46(2).

Tibbetts, John. (2002). "Coastal Cities: Living on the Edge” en, Environmental Health Perspectives. 110(11):674-681.

46 Vol. 1(1), Julio-diciembre, 2013: 11-21. Revista Nuevo Humanismo • ISSN: 1405-0234

[ pp. 23-46] 